\title{
Prescribing pattern of antibiotics among postoperative patients admitted in gynaecology and obstetrics department of tertiary care hospital in Northern India
}

\author{
Neeta Sawhney ${ }^{1}$, Vineeta Sawhney ${ }^{2 *}$, Vijay Khajuria ${ }^{2}$
}

\author{
${ }^{1}$ Department of Gynaecology and Obstetrics, SMGS Hospital, Government Medical College, Jammu, Jammu and \\ Kashmir, India \\ ${ }^{2}$ Department of Pharmacology, Government Medical College, Kathua, Jammu and Kashmir, India
}

Received: 25 November 2019

Revised: 10 January 2020

Accepted: 13 January 2020

\section{*Correspondence:}

Dr. Vineeta Sawhney,

Email: vineetasawhney@gmail.com

Copyright: (c) the author(s), publisher and licensee Medip Academy. This is an open-access article distributed under the terms of the Creative Commons Attribution Non-Commercial License, which permits unrestricted non-commercial use, distribution, and reproduction in any medium, provided the original work is properly cited.

\begin{abstract}
Background: The objective of the study was to study the prescribing pattern of the antibiotics in postoperative patients admitted in gynaecology and obstetrics.

Methods: Current prospective observational study was conducted in the department of pharmacology, Government Medical College, Kathua in collaboration with department of gynaecology and obstetrics for a period of six months duration from 1st May 2019 to 31st October 2019. The case sheets of all post operated patients above eighteen years of age admitted were studied and analyzed.

Results: Total of 1807 case sheets were analyzed and showed that 4245 antibiotics were prescribed with an average of 2.3 antibiotics prescribed. Oral cefuroxime (17.3\%) was maximally prescribed in patients who delivered normal presentation with episiotomy and injection ceftriaxone along with tinidazole and gentamycin were prescribed $(58.4 \%)$ where caesarean section was done. While injection ceftriaxone and sulbactum along with tinidazole and gentamycin (17.09\%) was prescribed in patients who were operated for gynaecological diseases. Maximum (80\%) of the antibiotics were prescribed under brand name.

Conclusions: Cephalosporin's are commonly prescribed antibiotic and in eighty percent brand names were prescribed. Results underscore that antibiotic in generic name should be encouraged.
\end{abstract}

Keywords: Antibiotics, Generic drugs, Brand name, Obstetrics and gynaecology

\section{INTRODUCTION}

Antibiotics are the most commonly prescribed drugs throughout the world. They are defined as the substances produced by the microorganisms, which selectively suppress the growth of or kill the other microorganisms at very low concentrations. ${ }^{1,2}$ Antibiotics are useful in treatment of number of infections and no doubt they have played a wider role in maintaining the longevity and improving quality of human life. But it has been observed that in maximum number of patients these are either not indicated or their use is inappropriate in terms of drug or dosage form. According to the results of the studies carried out in European countries and the United States, 23 to $38 \%$ of inpatients are given some kind of systemic antibiotic treatment. Antibiotics take the lead among the most commonly used drugs in Turkey and account for $20 \%$ of the drug market. ${ }^{3,4}$ In India, they account for more than $50 \%$ of the drugs sold and one of the study has shown that in $75 \%$ of the prescriptions, antimicrobials are prescribed and whether they are indicated or not is not clear but still they are prescribed. ${ }^{5}$ 
This irrational use of the antibiotics is responsible for producing antibiotic resistance and now it has become a serious problem in developing countries. Not only resistance but it also adds to cost of treatment, improper utilization of the drug and increases the mortality and morbidity, adverse effect and extended stay in the hospitals. So rational use of antibiotics has a very important role. Rational use of drugs encompasses that right drug should be prescribed to right patient in right dose in right dosage form and for right duration of time. As per World Health Organisation (WHO) rational use of drugs is "patients receiving medicines appropriate for their clinical needs, in doses that meet their individual requirements, for an adequate period of time and at the lowest cost to them and their community. ${ }^{6}$

Antibiotics are given not only for treatment of disease but also for the prophylaxis to prevent post-surgical wound infection which is primary cause of morbidity and mortality in patients undergoing surgery. Aseptic techniques during surgery do not completely eliminate bacterial infection and for that antibiotics are prescribed. The present study was conducted in our set up to evaluate the prescription pattern of antibiotics in postoperative patients.

\section{METHODS}

This prospective observational study was conducted in the department of pharmacology in collaboration with department of gynaecology and obstetrics of Government Medical College, Kathua. The duration of study was for a period of six month i.e. from $1^{\text {st }}$ May to $31^{\text {st }}$ October 2019. The case sheets of all the patients with age more than 18 yrs who were admitted in the wards of gynaecology and obstetrics department were included in the study and were analyzed. All pre-operative patients less than 18 yrs of age and those with incomplete case sheets were excluded from the study.

The study protocol was as per the guidelines of the declaration of Helsinki and ethical clearance was obtained from institutional ethical committee before starting the study. The IEC approved number is IEC/GMCK/04-05/pharma dated 15 April 2019. Data was collected regarding the patients age, indications for which they were operated, antibiotic prescribed, their dose, duration and route of administration was analyzed. Average number of antibiotics prescribed was calculated by dividing total number of antibiotics prescribed with number of case sheets analyzed. Drugs given alone, multidrug regimen and fixed drug combinations were calculated and presented as number and percentages.

\section{RESULTS}

In the present study, a total of 1807 case sheets were analyzed in six months which included both the patients admitted in gynaecology and obstetrics wards. Maximum numbers of these patients were operated for different indications which included 152 for gynaecological and 1655 for obstetrical indications. These postoperative patients were prescribed antibiotics of different categories. Age wise distribution of the patients showed that $980(54.2 \%)$ were in age group of 18 to $30 \mathrm{yrs}$ and $827(45.7 \%)$ were above 30 yrs. Table 1 showed that the most common indication for which the patients were admitted was pregnancy with normal delivery 1050 (58\%) and its various complications for which caesarean sections $605(33 \%)$ were done. The other indications for which surgery was indicated were mainly gynaecological 152 $(8.4 \%)$.

Table 1: Diagnosis of the patients admitted in wards $(n=1807)$.

\begin{tabular}{|lll|}
\hline S. no & Diagnosis & Number $(\%)$ \\
\hline $\mathbf{1}$ & Fibroid uterus & $26(1.4)$ \\
\hline $\mathbf{2}$ & UV prolapse & $20(1.1)$ \\
\hline $\mathbf{3}$ & Ca cervix & $10(0.5)$ \\
\hline $\mathbf{4}$ & Chronic cervicitis & $07(0.38)$ \\
\hline $\mathbf{5}$ & Adenexed mass & $08(0.4)$ \\
\hline $\mathbf{6}$ & Ovarian cyst & $20(1.1)$ \\
\hline $\mathbf{7}$ & Others & $81(4.48)$ \\
\hline $\mathbf{8}$ & Full term pregnancy and normal delivery & $1050(58)$ \\
\hline $\mathbf{9}$ & Caesarean sections & $605(33)$ \\
\hline
\end{tabular}

Table 2: Frequency of antibiotics prescribed $(n=4245)$.

\begin{tabular}{|lllll|}
\hline S. no & Antibiotics & Number $(\%)$ & Dose & Dosage \\
\hline $\mathbf{1}$ & Ceftriaxone & $462(10.88)$ & $1 \mathrm{gm} \mathrm{BD}$ & Intravenous \\
\hline $\mathbf{2}$ & Ceftriaxone with sulbactum & $240(5.6)$ & $1.5 \mathrm{gm} \mathrm{BD}$ & Intravenous \\
\hline $\mathbf{3}$ & Gentamycin & $530(12.48)$ & $80 \mathrm{mg}$ TDS & Intramuscular \\
$\mathbf{4}$ & Amikacin & $76(1.7)$ & $250 \mathrm{mg} \mathrm{BD}$ & Intramuscular \\
\hline $\mathbf{5}$ & Tinidazole & $702(16.5)$ & $1 \mathrm{gm} \mathrm{BD}$ & Intravenous, oral \\
\hline $\mathbf{6}$ & Piperacillin and tazobactum & $40(0.94)$ & $4.5 \mathrm{gm} \mathrm{BD}$ & Intravenous \\
\hline
\end{tabular}




\begin{tabular}{|lllll|}
\hline S. no & Antibiotics & Number $(\%)$ & Dose & Dosage \\
\hline $\mathbf{7}$ & Amoxycillin & $120(2.8)$ & $500 \mathrm{mg}$ TDS & Oral \\
\hline $\mathbf{8}$ & Framycetin & $1050(24.7)$ & $1 \%$ skin cream & Locally \\
\hline $\mathbf{9}$ & Amoxycillin and clavulanic acid & $280(6.59)$ & $625 \mathrm{mg}$ BD & Oral \\
\hline $\mathbf{1 0}$ & Linezolid & $10(0.23)$ & $600 \mathrm{mg}$ BD & Oral \\
\hline $\mathbf{1 1}$ & Cefuroxime & $735(17.3)$ & $500 \mathrm{mg}$ BD & Oral \\
\hline
\end{tabular}

Table 3: Antibiotics prescribed as multidrug regime $(n=702)$.

\begin{tabular}{|c|c|c|c|c|}
\hline S. no & Antibiotics in combination & Number $(\%)$ & $\begin{array}{l}\text { Duration of } \\
\text { treatment }\end{array}$ & $\begin{array}{l}\text { Brand/generic } \\
\text { form }\end{array}$ \\
\hline 1 & Ceftriaxone and tinidazole & $52(7.4)$ & 7-10 days & Generic \\
\hline 2 & $\begin{array}{l}\text { Ceftriaxone, tinidazole and } \\
\text { gentamycin }\end{array}$ & $410(58.4)$ & 10-12 days & Generic/brand \\
\hline 3 & $\begin{array}{l}\text { Ceftriaxone, sulbactum and } \\
\text { tinidazole }\end{array}$ & $44(6.26)$ & $7-10$ days & Brand/generic \\
\hline 4 & $\begin{array}{l}\text { Ceftriaxone, sulbactum, tinidazole } \\
\text { and gentamycin }\end{array}$ & $120(17.09)$ & 10-14 days & Brand/generic \\
\hline 5 & $\begin{array}{l}\text { Ceftriaxone, sulbactum, tinidazole } \\
\text { and amikacin }\end{array}$ & $30(4.27)$ & 10-14 days & Brand/generic \\
\hline 6 & $\begin{array}{l}\text { Ceftriaxone, tinidazole and } \\
\text { amikacin }\end{array}$ & $46(6.5)$ & 10-12 days & Brand/generic \\
\hline
\end{tabular}

Table 4: Antibiotics prescribed as fixed drug combination (n=560).

\begin{tabular}{|lllll|}
\hline S.no & Antibiotics & Number $(\%)$ & Dose & Dosage \\
\hline $\mathbf{1}$ & Ceftriaxone with sulbactum & $240(5.6)$ & $1.5 \mathrm{gm} \mathrm{BD}$ & Intravenous \\
\hline $\mathbf{3}$ & Piperacillin and tazobactum & $40(0.94)$ & $4.5 \mathrm{gm} \mathrm{BD}$ & Intravenous \\
\hline
\end{tabular}

A total of 4245 antibiotics were prescribed with average of 2.3 antibiotics per prescription. Regarding antibiotic prescription the results showed that cefuroxime 735 $(17.3 \%)$ orally was commonly prescribed in the patients who delivered normally along with framycetin 1050 $(24.7 \%)$ which is applied locally (Table 2 ).

A total of 702 case sheet analysis showed that antibiotics were prescribed as multidrug regime. It was seen that those who have undergone surgery for complicated pregnancy ceftriaxone along with tinidazole infusion and gentamycin $410(58.4 \%)$ in injection form was maximally prescribed and those patients who were operated for gynaecological diseases was prescribed with injection ceftriaxone sulbactum in combination with tinidazole, and gentamycin $120(17.09 \%)$ (Table 3).

Those patients where complications were seen during surgery were given a higher group of antibiotics piperacillin and tazobactum. Antibiotics were commonly prescribed orally for 7 to 10 days in patients who delivered normally whereas in patients where caesarean was done antibiotics were given initially for 7 to 10 days in injectibles form followed by oral therapy for 7days whereas in gynaecological cases antibiotics were given as injectibles for 10 to 15 days. In 560 case sheet analysis amoxycillin, clavulanic acid as fixed dose combination was maximum prescribed $280(6.59 \%)$ followed by ceftriaxone with sulbactum in $240(5.6 \%)$ cases.

\section{DISCUSSION}

Antibiotics are $2^{\text {nd }}$ most commonly prescribed drugs in the world. ${ }^{7}$ Antimicrobials are frequently used as prophylaxis to prevent postoperative infection at surgical site. However, current WHO guidelines do not recommend routine antibiotic prophylaxis for women undergoing operative vaginal birth because of insufficient evidence of effectiveness. ${ }^{8}$

Few of studies have been done in India to analyze the antibiotic usage in postoperative patients admitted in gynaecology department. ${ }^{9}$ The current study was done in one of the teaching hospital of northern India. In our study, maximum number of patients were in age group of less than 30 years and were admitted as full term pregnancy with normal delivery and these patients were prescribed with oral antibiotic cefuroxime $(17.3 \%)$ and amoxycillin clavulanate $(6.59 \%)$ for 7 to 10 days and it is in concurrence with other studies. ${ }^{10}$ The antibiotic prescribed after caesarean section in our study was ceftriaxone in combination with tinidazole and gentamycin. Use of antibiotic prophylaxis is widely recommended after caesarean section because there is a clear systematic review that it reduces incidence of 
maternal infection. ${ }^{11}$ Third generation cephalosporin were also observed to be commonly used in other studies also. ${ }^{10,12}$ This group of drugs are highly potent and have wide spectrum, active against both gram positive and gram negative organisms and in present study maximum of the antibiotics after surgical intervention was cephalosporin.

The percentage of drugs prescribed by generic name was found to be low in our study and maximum number of the drugs were prescribed by the brand name i.e. is more than $(80 \%)$ whereas in another study, drugs prescribed in generic name was $37.71 \% .^{13,14}$ The average number of antibiotic per prescription in this study was 2.3 and similar average number of antibiotics has been reported earlier. $^{14}$

In our study maximum number of patients received preparations in parental dosage form and (48\%) antibiotics were used as injectables and $(26.9 \%)$ as oral preparations and $(24.7 \%)$ as local preparations and similar results were seen in other study done by Devi et al where (63.01\%) antibiotics were given by parenteral therapy and $(29.14 \%)$ as oral preparation and $(0.37 \%)$ locally. ${ }^{15} \mathrm{In}$ present study $(38.8 \%)$ of antibiotics as multidrug regime were used and is concurrence with other studies. ${ }^{16}$ Antibiotics were given as fixed dose combinations and amoxicillin in combination with clavulanic acid was prescribed maximum in $(6.59 \%) 280$ case sheets and was similar in one study where it was prescribed $40 \% .{ }^{17}$

\section{CONCLUSION}

From the present study it is concluded that ceftriaxone is commonly used in postoperative patients. Those antibiotics were prescribed in generic name only which were available in hospital pharmacy. Patients who underwent normal delivery with episiotomy were prescribed amoxicillin and cefuroxime. All these antibiotics were prescribed without culture sensitivity which has to make mandatory in the hospital before antibiotic prescription.

Poly-pharmacy was seen in large extent as 2 to 3 antibiotics were prescribed which can be avoided by using broad spectrum antibiotic. Prescribing the antibiotic in generic name should be encouraged.

Funding: No funding sources

Conflict of interest: None declared

Ethical approval: The study was approved by the Institutional Ethics Committee

\section{REFERENCES}

1. Tripathi KD. Antimicrobial drugs: General Considerations. Essentials Med Pharmacol. 2019;688:739.
2. Ahmad A, Megha R, Irfanul H, Pravina A. Study the prescription pattern of antibiotics in the medicine department in a teaching hospital. IJTPR. 2014;6(3):43-6.

3. Ramesh A, Salim S, Gayatri AM, Uma N, Retanavally KG. Antibiotics prescribing pattern in the in-patient departments of a tertiary care hospital. Arch Pharm Pract. 2013;4:71.

4. Alenazi SA, Koura HM. Evaluation of therapeutic use of antibiotics in arar central hospital Saudi Arabia. J Appl Sci Res. 2013;9:368-74.

5. Vanitha M, Vineela M. Prescribing pattern of antibiotics in patients attending ENT OPD in a tertiary care hospital. ISOR-JDMS. 2017;16(9)-30-3.

6. Tripathi KD. Aspects of Pharmacotherapy, clinical Pharmacology and drug development. Essentials Med Pharmacol. 2019;81.

7. Tunger O, Dinc G, Ozbakkaloglu B, Atman UC, Alqun U. Evaluation of rational antibiotic use. Int $\mathbf{J}$ Antimicrobial Agents. 2000;15(2):131-5.

8. WHO recommendation on antibiotics for uncomplicated vaginal birth. Available at: https://extranet.who.int. Accessed on 17th February 2018.

9. Kolasani BP, Sasidharan P, Divyashanthi CM. A prospective study of prescribing pattern of drugs among in-patients of gynaecology department in a tertiary care teaching hospital in South India. Int $\mathbf{J}$ Basic Clin Pharmacol. 2016;5(4):1321-6.

10. Sharma M, Sanneving L. Antibiotic prescribing in women during and after delivery in a non-teaching, tertiary care hospital in Ujjain, India: a prospective cross-sectional study. J Pharma Policy Pract. 2013;6:9.

11. Liu R, Lin L, Wang D. Antimicrobial prophylaxis in caesarean section delivery. Exp Therap Med. 2016;12(2):961-4.

12. Agarwal M, Nayeem M, Shafhi MM, Makeen HA, Sumaily MJ, Gupta N. Prescribing pattern of drugs in the department of obstetrics and gynaecology in expecting mothers in jazan region, KSA. Int $\mathbf{J}$ Pharma Pharma Sci. 2014;6(1):658-61.

13. Bhingare PE, Bashir MSM, Khade A, George S. Prescription pattern in Gynaecology - A retrospective study in a south Indian Teaching Hospital. J Cont Med A Dent. 2014;2(2):51-4.

14. Dwivedi YK. Prescribing pattern of antimicrobial agents in patients suffering from PID in a tertiary cae teaching hospital. Indian J Basic Applied Med Res. 2013.

15. Thadibouine MD, Adithya SB, Vadivel K. Drug utilization in post-operative patients in obstetricsGynaecology and Surgical Gastroentrology Department- A retrospective study. Int J Pharm Pharma Sci. 2018.

16. Islam MM, Saha SK, Saha S, Wahid UA, Gomes RR, Ahmed KS, et al. Current Trends of using Antimicrobials at obstetrics and Gynaecology Department in a Tertiary care Hospital. Mymensingh Med J. 2017;26(3):514-8. 
17. Gor AP, Ambani A, Dalal K. Use of Fixed dose combinations of antibiotics in a surgical department of atertiary care teaching hospital. Int J Pharma Pharma Sci. 20157(11):259-62.
Cite this article as: Sawhney N, Sawhney V, Khajuria V. Prescribing pattern of antibiotics among postoperative patients admitted in gynaecology and obstetrics department of tertiary care hospital in Northern India. Int J Basic Clin Pharmacol 2020;9:300-4. 